\title{
Sustainable financing of health promotion services in selected countries: Best experience for developing countries
}

\author{
Hamideh Javadinasab ${ }^{1}$, Iravan Masoudi AsI*2, Abbas Vosoogh-Moghaddam ${ }^{3,4}$, Behzad Najafi5,6 \\ Received: 4 Jul 2018 \\ Published: 5 Jun 2019
}

\section{Abstract}

Background: Sustainable health financing is one of the main challenges of policymakers in the health system. Thus, this study aimed to investigate the sustainable financing of health promotion services in 7 selected countries and to analyze the related documents in Iran in 2018.

Methods: This was a comparative and qualitative study (document analysis). In the comparative phase, the studies related to the selected countries- Australia, England, Germany, Japan, Turkey, Sweden, and Denmark- were investigated. In the second phase of the study, through a qualitative method of content analysis, 60 related documents were examined from 2005 to 2018 . The initial evaluation of the documents was done using the Scott method and data were analyzed using Nvivo 8 software.

Results: Based on the main findings of the study, there were a variety of approaches to the sustainable financing of health promotion services: excise taxes on goods; health-related behaviors regarding tobacco and alcohol consumption and gambling; using the capacities of social insurance funds in Germany and Turkey; and relying on the government budget in all the studied countries. According to the results of documents analysis related to the sustainable financing of health promotion in Iran, 3 main issues and 11 sub issues were identified.

Conclusion: Using any of these methods or a combination of them depends on the political, social, and cultural structure of each country. The provisions of the law seem to be almost comprehensive; however, implementation, operationalization and monitoring of these elements are of significant importance.

Keywords: Health promotion, Iran, Excise tax, Sustainable financing, Sin tax

Conflicts of Interest: None declared

Funding: None

*This work has been published under CC BY-NC-SA 1.0 license.

Copyright@ Iran University of Medical Sciences

Cite this article as: Javadinasab H, Masoudi Asl I, Vosoogh-Moghaddam A, Najafi B. Sustainable financing of health promotion services in selected countries: Best experience for developing countries. Med J Islam Repub Iran. 2019 (5 Jun);33:52. https://doi.org/10.47176/mjiri.33.52

\section{Introduction}

Non-communicable diseases account for $43 \%$ of the worldwide burden of diseases and they are expected to account for $60 \%$ of the total burden of diseases by 2020 and $73 \%$ of all deaths. These diseases account for $50 \%$ of the annual deaths and $60 \%$ of the burden of diseases in the

\footnotetext{
Corresponding author: Dr Iravan Masoudi Asl, masoudi@majles.ir
}

1. Department of Health Services Management, Science and Research Branch, Islamic Azad University, Tehran, Iran

2. Department of Health Services Management, School of Health Management and Information Sciences, Iran University of Medical Sciences, Tehran, Iran

3. Faculty member of secretariate for supreme council of health and food security, Ministry of Health and Medical Education, Tehran, Iran

4. NCD Research Center, Endocrine and Metabolism Research Institute, Tehran University of Medical Sciences and Health Services, Tehran, Iran.

5. Iranian Center of Excellence in Health Management, Department of Health Services Management, School of Management and Medical Informatics, Tabriz University of Medical Sciences, Tabriz, Iran

6. Department of health economics, School of Management and Medical Informatics, Tabriz University of Medical Sciences, Tabriz, Iran
Eastern Mediterranean region. Thus, cardiovascular diseases, chronic pulmonary diseases, stroke, and type 2 diabetes account for 3 causes of the first 6 causes of mortality (1). In Iran, non-communicable diseases are responsible for $45 \%$ and $33 \%$ of the burden of diseases in men and

\section{$\uparrow$ What is "already known" in this topic:}

Resources allocated to health promotion are not sustainable and change according to the country's budget policies and priorities. The accumulation of taxes/ sin tax of harmful goods and services and allocating them to health promotion can improve the public health and reduce the burden of diseases and imposed costs on the health system.

\section{$\rightarrow$ What this article adds:}

There are a variety of approaches to sustainable financing of health promotion services in Iran: taxes/sin tax on unhealthy foods, sweetened beverages \& services; using the capacities of social insurance funds; and relying on government's budget. 
women with any causes. Obesity and overweight, hypertension, inadequate physical activity, hypercholesteremia, and addiction are among the first 5 risk factors that account for $11 \%$ of the total burden, $68 \%$ of the burden of risk factors, and 1.6 million of DALYs (2). Tobacco use, unhealthy diet, inadequate physical activity, and alcohol abuse are among the most important risk factors for noncommunicable diseases. Therefore, designing public and private interventions, such as health promotion programs, are necessary to reduce the contribution of these factors (3).

Health promotion is one of the principals of the community health development that helps to improve health. Health promotion not only involves direct actions to strengthen the skills and abilities of individuals, but also focuses on changing social, environmental, and economic situations to reduce their impact on the health of individuals and the general population (4). With this comprehensive definition of health promotion, the 1986 Ottawa Declaration urged countries and organizations to align their health services with basic infrastructure, such as shelter, education, food, income, social justice and justice, and resources, to redirect to health promotion. In 1997, the Jakarta Declaration emphasized the importance of shifting resources towards health promotion. In 2005, the Bangkok Declaration encouraged countries to promote health promotion as the primary responsibility of governments by shifting the priority of investments inside and outside the health sector and providing sustainable resources for health promotion (5).

Funding resources are vital elements of health care; however, spending more does not necessarily have better health outcomes (6). By changing the lifestyle and the age pyramid of the society, attention is paid to preventive approaches and health promotion $(7,8)$. Health promotion, which is a cost-effective method to improve and maintain the population health, needs support; however, health financing has not been sufficiently considered, and this issue has not gained importance compared to health care services $(9,10)$. On the other hand, in many countries, funding is limited to hospitals and health care organizations; for example, in Asia and Oceania, 70\% of the essential interventions, including primary prevention and care, account for less than $10 \%$ of the resources (11).

Choosing the best method to provide sustainable financial resources is one of the most important challenges of policymakers and health system planners; and this challenge becomes more complicated as the need for public services increases $(12,13)$. On the other hand, citizen health care costs have increased at a considerable pace, which in turn has created additional pressure on insurers, policymakers, and the public (14). To stabilize the health system, its financing needs to be sustained, and the emphasis on the need for sustainability of health financing sources will make the services available to health applicants without any concern or interruption (15).

Andreyeva et al (2011) have shown that excise taxes on sugar sweetened beverages by the government can directly prevent obesity (16). Moody et al (2013) also pointed out that market interventions and formulation of gen- eral rules are necessary given the harmful effects of smoking, alcohol, and some foods and drinks, and they also indicated that the benefits of preventing harmful effects should be investigated (17). In the study of Miton (2007), the effect of the value added tax (VAT) on nutrition and health in England was estimated (18). The main challenge of improving the health system in any economy is its financial resources, and policymakers always aim to obtain these sources to improve the health standards of their community. Health promotion resources in different countries can be provided through public budgets, insurance funds, and designing specific interventions to increase the financial capacity of health promotion (19-21).

Therefore, given the mentioned challenges and the necessity of implementing the above rules, identifying sustainable sources of funding for health promotion services is essential. Hence, the present study aimed to compare sustainable financing in the field of health promotion in selected countries and to analyze the existing policy documents in Iran in 2018.

\section{Methods}

This was a comparative and qualitative study (policy analysis). Web of Science, PubMed, Science Direct, and Scopus were searched to find relevant studies conducted since 1990. In the comparative phase, the retrieved studies were reviewed. Presence of an English abstract as a search restriction was identified, and searching was done using the search strategies (Table 1).

In the first step, articles were extracted: PubMed: 820, Web of Science: 1212, Science Direct: 752, Scopus: 506.

The articles were given to the authors for review of the abstracts and selection of more related articles; the number of articles was reduced at the end of this step: PubMed: 115, Web of Science: 234, Science Direct: 175, Scopus: 86.

In the next step, the selected articles were fully read and the items were extracted based on the framework of the article.

Furthermore, to find more reports and documents, various databases, such as the World Health Organization (WHO), the World Bank, and Google search engine, were searched with the following key words: "Financing of Health Promotion Services" and "Health Tax". In this study, there were countries with experiences in sustainable financing of health promotion services, and there were also reliable and accessible sources and articles. The next criterion for choosing countries was their similarity to Iran in gross domestic product (GDP). Samples have also been selected from all economic systems around the world (eg, countries with free market economy, etc.). Therefore, all selected countries had one or more of the mentioned criteria (Australia, England, Germany, Japan, Turkey, Sweden, and Denmark).

In this study, to collect related data from the selected countries, a data extraction form, which was designed based on the purpose of the study, was used. To analyze and compare the data, comparative tables were used in this stage, which included comparing the dimensions obtained from the study of sustainable financing in the area 
Table 1. Search strategies

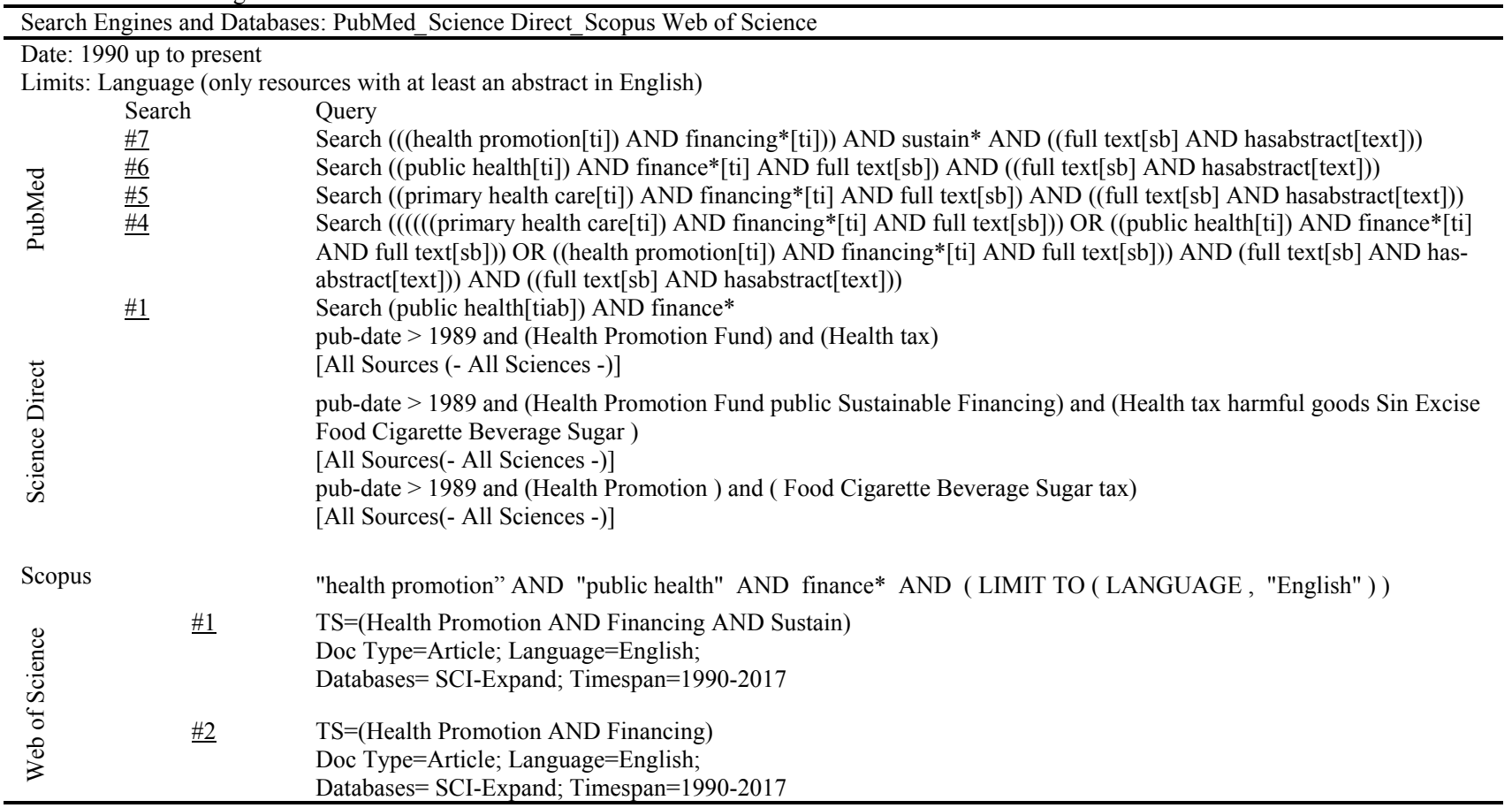

of health promotion in selected countries. Therefore, the comparative table was completed with the extracted data and it was the basis for analyzing and comparing the countries.

In the second phase of the research, by qualitative method of content analysis, the existing documents related to the topic were investigated from the beginning of the fourth program of economic, social and cultural development of IR. Iran (1985-2007). In this phase, all the policy documents dealing with the issue of sustainable financing for the improvement of health and the health system as a whole were purposely selected and analyzed during 20052017, which were as follow: fourth, fifth, and sixth programs for social, economic, and cultural development of the country ( 3 documents); budget laws and their implementing rules (2005-2017) (26 documents); and documents related to sustainable financing and promotion of health, including the law of the incorporation of certain articles into the law of regulating part of the financial regulations of the government, the law of the permanent regulations of the country development plans, the law of value added tax, subsidy programs (5 documents), policies related to the provision of sustainable financing and promotion of health ( 9 documents), and other laws and documents (17 documents). After collecting the documents, the four-step Scott method (Authentication, Validation, Data Representation, and Meaningfulness) was used to extract the desired documents. The originality of the Scott method means that the reference to these documents, directives, and circulars is authentic. The criterion of validity, referring to the belief in the objective and subjective components, has a source or message. Valid documents should not be misleading; they should be free of errors, and in general, should not have personal and organizational advantage. Representation means that the examined documents are representative of the general policies or specified keywords. Meaningfulness, the last step in the Scott method, means that the document is transparent and comprehensive and has some form of face and content validity, indicating that all the dimensions of appearance, format, and content are valid. The Scott method, which proposes a 4-step procedure for document review, has been used to extract the related documents in this study.

After implementing the Scott method, documents were explicitly and implicitly analyzed. Nvivo 8 software was used for content analysis.

\section{Results}

The findings of the comparative phase were divided into 4 areas: (1) the mode and type of health system budget allocation, (2) taxable goods and services, (3) the rules and regulations for obtaining taxes, and (4) stakeholders involved in sustainable financing of health promotion (2227) (Table 2).

Based on the results of the analysis of documents related to sustainable financing of health promotion in Iran, 3 main issues and $11 \mathrm{sub}$ issues were identified.

\section{1- Financing}

1-1 Sustainable financing: Increasing the health contribution of the GDP and the government budget; providing sustainable health financing in the health sector with an emphasis on transparency of incomes, costs and activities; allocating $40 \%$ of the health expenditure to free villagers' insurance program for providing first-level services by the Ministry of Health; increasing the price of drugs with an abusive potential by $100 \%$; using taxes and popular contributions to increase health care revenues; providing $5 \%$ of the total health resources from revenues from tourism therapy; allocating $10 \%$ refunds of the sin tax in Article 
Table 2. Budget allocation, taxable goods, rules and regulations for obtaining taxes, and stakeholders involved in sustainable financing in the selected countries

\begin{tabular}{|c|c|c|c|c|}
\hline 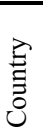 & $\begin{array}{l}\text { Mode and type of health } \\
\text { system budget allocation }\end{array}$ & $\begin{array}{l}\text { Taxable goods } \\
\text { and services }\end{array}$ & $\begin{array}{l}\text { Stakeholders involved in the sus- } \\
\text { tainable financing }\end{array}$ & $\begin{array}{l}\text { Obligations to collect taxes and the way to } \\
\text { monitor the implementation }\end{array}$ \\
\hline 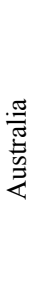 & $\begin{array}{l}\text { Global flexible budget } \\
\text { Allocation of the basis of } \\
\text { service volume and service } \\
\text { cost } \\
\text { Federal-controlled allocation } \\
\text { Allocated tax method }\end{array}$ & $\begin{array}{l}\text { Alcohol } \\
\text { Tobacco } \\
\text { Luxury cars } \\
\text { Gambling }\end{array}$ & $\begin{array}{l}\text { Ministry of Health and Paramedics } \\
\text { Central government } \\
\text { State and local governments } \\
\text { Tax office } \\
\text { People paying taxes }\end{array}$ & $\begin{array}{l}\text { The tax on alcohol in terms of concentration } \\
\text { in liters. } \\
\text { The tax on cigarettes with } 0.8 \text { grams of to- } \\
\text { bacco per cigarette. } \\
\text { The rates have doubled according to con- } \\
\text { sumer price index. } \\
\text { The tax on luxury cars based on the GST list. } \\
\text { The tax on gambling varies from country to } \\
\text { country }\end{array}$ \\
\hline 를 & $\begin{array}{l}\text { Global flexible budget } \\
\text { Allocation based on priorities }\end{array}$ & $\begin{array}{l}\text { Alcohol } \\
\text { Tobacco }\end{array}$ & $\begin{array}{l}\text { National Medical Office } \\
\text { zonal and regional health offices } \\
\text { Public funds managers }\end{array}$ & $\begin{array}{l}\text { The tax on alcohol and tobacco varies by } \\
\text { type. In addition, general goods tax is also } \\
\text { obtained }\end{array}$ \\
\hline 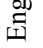 & and constraints & Gambling & Ministry of Finance & The gambling tax varies according to its type. \\
\hline 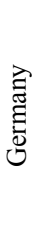 & $\begin{array}{l}\text { Global flexible budget } \\
\text { Allocation criteria: Quality of } \\
\text { service, cost of services, } \\
\text { volume of services, number } \\
\text { of people covered by services }\end{array}$ & $\begin{array}{l}\text { Alcohol } \\
\text { Tobacco } \\
\text { Coffee } \\
\text { Energy tax on } \\
\text { natural resources } \\
\text { such as oil, coal } \\
\text { and gas }\end{array}$ & $\begin{array}{l}\text { Health insurance funds } \\
\text { Pension funds } \\
\text { Fund and municipalities } \\
\text { Federal government } \\
\text { Local government }\end{array}$ & $\begin{array}{l}\text { In addition to } 19 \% \text { of the general tax, excise } \\
\text { taxes are also imposed on these goods. } \\
\text { Currently tobacco tax is } 52 \% \\
\text { Coffee taxes vary from } \$ 2.19 \text { to } \$ 4.78 \text { per } \\
\text { kilo. } \\
\text { The alcohol tax varies depending on its type. }\end{array}$ \\
\hline 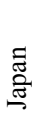 & $\begin{array}{l}\text { Central budget } \\
\text { Local budget } \\
\text { Allocation and oversight by } \\
\text { the government }\end{array}$ & $\begin{array}{l}\text { Alcohol } \\
\text { Gasoline } \\
\text { Tobacco }\end{array}$ & $\begin{array}{l}\text { Federal and local government } \\
\text { Ministry of Health, Welfare and } \\
\text { Finance }\end{array}$ & $\begin{array}{l}\text { There are no tax revenues in this country } \\
\text { specifically for healthcare costs. }\end{array}$ \\
\hline $\begin{array}{l}\frac{D}{0} \\
\frac{D}{0} \\
\vdots \\
\infty\end{array}$ & $\begin{array}{l}\text { Central budget } \\
\text { Allocation by local councils } \\
\text { according to the councils and } \\
\text { covered population }\end{array}$ & $\begin{array}{l}\text { Alcohol and gam- } \\
\text { bling } \\
\text { Tobacco } \\
\text { Fuel, energy, and } \\
\text { motor vehicles }\end{array}$ & $\begin{array}{l}\text { Department of Finance } \\
\text { Local councils } \\
\text { Ministry of Health }\end{array}$ & $\begin{array}{l}\text { In addition to } 25 \% \text { of the general tax, excise } \\
\text { taxes are also levied on these goods } \\
\text { Currently tobacco tax is } 48.5 \% \\
\text { The alcohol tax varies depending on its type } \\
\text { The gambling tax is } 30 \%\end{array}$ \\
\hline$\underset{\substack{\vec{\partial} \\
\Xi}}{\stackrel{\partial}{\Xi}}$ & $\begin{array}{l}\text { Central budget } \\
\text { By the Ministry of Health and } \\
\text { allocations based on costs } \\
\text { incurred and inflation rates }\end{array}$ & $\begin{array}{l}\text { Alcohol } \\
\text { Tobacco }\end{array}$ & $\begin{array}{l}\text { Ministry of Health } \\
\text { Social Security Insurance } \\
\text { Insurance funds } \\
\text { Department of Finance }\end{array}$ & $\begin{array}{l}\text { The tax on alcohol varies according to the } \\
\text { type and amount of alcohol. } \\
\text { All kinds of alcoholic beverages are taxed. } \\
\text { The tax rate for tobacco is now } 74 \% \text {. }\end{array}$ \\
\hline 亳 & $\begin{array}{l}\text { Central budget based on } \\
\text { demographic and regional } \\
\text { differences. } \\
\text { Municipalities and councils }\end{array}$ & $\begin{array}{l}\text { Alcohol } \\
\text { Tobacco }\end{array}$ & $\begin{array}{l}\text { Ministry of Health at the state level } \\
\text { Local and regional governments } \\
\text { Municipalities }\end{array}$ & $\begin{array}{l}\text { Alcohol is taxed as a consumable commodity. } \\
\text { The tobacco tax rate is } 54.75 \% \text {. }\end{array}$ \\
\hline
\end{tabular}

38 (section A) of the value added tax law to improve the health and skills of employees; providing sustainable financing for the health sector; and the quantitative and qualitative development of health insurance.

1-2 Sin tax for unhealthy foods, sweetened beverages, and services: Providing a list of measures and unhealthy (or less healthy) foods, sweetened beverages \& services, and drugs; percentage of excise tax for the mentioned commodities at the beginning of each year by the working group supervised by the Ministry of Health and Medical Education and with the membership of the Ministries of Economic Affairs and Finance, Commerce, Welfare and Social Security, Industries and Mines, and the Plan and Budget Organization; Prohibition of advertising health threatening goods; and setting tax on unhealthy foods, sweetened beverages, and services.

1-3 Tobacco tax: Taxing each packet of any kinds of cigarettes, pipe tobacco, and ready to use tobacco; imposing tax on cigarette retailers to reduce tobacco consump- tion and to educate, prevent, and treat related illnesses; providing rehabilitation and treatment to those with complications resulting from tobacco consumption and promoting sports, especially general sports at schools; and limiting tobacco products entry by foreign travelers through collecting taxes (The VAT rate of tobacco products is $12 \%$.).

1-4 Value added tax (VAT): Allocating a percentage of VAT as a health tax.

1-5 Subsidy program: Allocating 10\% of subsidy program, in addition to health sector budget, to health equity and reducing out-of-pockets to $30 \%$ of health costs; providing fair access to health services; helping to pay for catastrophic health expenses, drug coverage, offering treatment to those with specific or severe health problems; and reducing dependency in health care affairs.

1-6 Pollution charges: Obtaining pollution charges in cities with population of over 1 million to deal with environmental pollution and to help develop public transporta- 
tion; and having oil refineries and petrochemical units pay $1 \%$ of their selling price as pollution costs until the elimination of pollution.

\section{2- Health promotion}

2-1 Health and prevention: Promoting public health and education; controlling and preventing contagious diseases and pests; coping with and mitigating the effects of natural and public disasters as governance affairs; knowledge of prevention and promotion of health with an emphasis on high burden diseases and indigenous dilemmas; healthy lifestyle patterns consistent with the Islamic teachings; using indigenous nutrition patterns of health and technology priorities; informing people about dangers of cigarette smoke and tobacco products; setting bills and laws by the Ministry of Health to control tobacco; allocating at least $5 \%$ of public health budgets to health promotion; increasing the allocation of family doctor's resources and referral system to at least $50 \%$ of all health resources; and tobacco control at the national, regional, and international levels.

2-2 Reducing health risks: Preparing a bill to reduce health risks in the workplace, air, water, and soil, agricultural and livestock products pollutants and specification; the amount and method of collecting compensatory charges and offenses and the way of using resources should be approved in the parliament; and preventing the advertisement of services and health-damaging goods based on Article 48 of the incorporation law, and controlling the environmental pollution.

\section{3- Justice in health}

3-1 Reducing out-of-pocket payments: Allocating credit for vulnerable households in the annual budget bill; reducing the share of low-income and vulnerable households in their health and treatment costs; developing a mechanism to cover those who cannot afford to participate; and using charities to pay high costs.

3-2 Expanding social insurance: Providing free basic insurance packages for all groups based on their affordability through referral system and family physicians at university centers and charging a premium in the case they need more services; and allocating part of the subsidy program for provision of social insurance, health services, community health, and a coverage for drugs and treatment of refractory diseases.

3-3 Leveling health services: Designing a system for providing the minimum standard of health care services in the country based on service levels to provide fair access to health services, and rationalizing it in accordance with the needs of different regions.

\section{Discussion}

Conducting studies and evaluating sustainable financing in the field of health promotion can help to improve the general health, reduce the burden of diseases, and costs imposed on health systems (28). The present study aimed to investigate sustainable financing methods for health promotion services in 7 selected countries and to analyze the related documents in Iran. The effectiveness of poli- cies developed in different countries and their impact on the consumption of unhealthy foods, sweetened beverages $\&$ services, and choosing the type of resources allocation from these policies to health promotion activities are 2 important issues in the sustainable financing of health promotion services. The findings of this study showed that excise tax on unhealthy foods, sweetened beverages \& services, and allocation of these resources to health promotion services have been done in most of the studied countries. In this regard, the main products, with a maximum agreement, were tobacco and alcohol. The analysis of documents in Iran also showed that attempts have been made to impose charges on tobacco products in the country, which was first considered in Iran's budget law in 2005; however, it has not been promoted as an accepted approach among all policymakers of the country. In other words, basic steps have been taken in this field, but more attention is needed to achieve effective outcomes. Generally, taxing unhealthy foods, sweetened beverages \& services is a successful way to finance health promotion services. In these commodities, determining sin tax can lead to behavioral change and also provide appropriate resources for health promotion activities (29). Evans and Pabloos Mendez (2016) showed that settling taxes/sin tax on unhealthy foods, sweetened beverages \& services and increasing the price had reduced their consumption. Thus, for $10 \%$ increase in the price of harmful commodities, the total consumption would be reduced to $4 \%$ in developed countries and $8 \%$ in developing countries (30). Good Child et al (2016), by examining the impact of an increase of $\$ 1$ on a 20-digit cigarette pack in 181 countries and quantifying this impact, concluded that the increase in tobacco taxes, in addition to the impact of preventing the death rate and helping to achieve sustainable development goals, can be considered as an appropriate source for increasing the financial capacity of the health system (31). The price of cigarettes in Iran is very low compared to their global price, and due to their low price, the excise tax policy on them is in the early stages. By tax/sin tax levied on smoking as a control tool, the long-term public health can be improved and smoking can be reduced. Moreover, more taxes/charges on smoking and tobacco can create an important source of income and sustainable financing to control and prevent non-communicable diseases and promote public health (32).

Based on the study findings, the use of capacities of social insurance funds in Turkey and Germany is one of these methods. In Iran, the expansion of social insurance for health promotion services was shown in the analysis of policy documents. The same insurance methods used in the sustainable financing of health promotion services in Mongolia in the study of Bayarsayekhan and Nakamura (2009) also demonstrated the effectiveness of this financing method. Although financing specification of health promotion services through social insurance is a new approach, this study showed that in the long run, investing in health promotion services has a significant role in reducing the costs of social insurance funds (21). Increasing financial capacity in health promotion services, either through public funds or through social funds depending on 
the country financing system, can lead to more preventive measures in this service.

The resources of taxes/sin tax can be used to reduce consumption, prevention, and treatment to develop education and to promote sports. One of the most important methods of reducing the consumption of unhealthy foods, sweetened beverages \& services is to increase their prices and excise taxes. Various research studies have also approved this method. Comparative findings and analysis of documents generally address the following 6 pillars: (1) access forbidden for minors, (2) consumption prohibition in public places, (3) providing more information to the public in terms of the risk of consumption, (4) providing a field of smoking cessation, (5) increasing prices through taxation, and (6) researching and monitoring about the implementation of these policies, which are the essential parts of the executive strategies.

Comparative research studies have some limitations. The information is published in the form of official reports on the websites of the Ministry of Health, and is often in Farsi, and not published in scientific journals, which makes it difficult to achieve comprehensive findings.

On the other hand, in the present study, although the experience of different countries in the field of legal and policy issues has been addressed, the executive fate of the enacted laws remains unclear and the way of spending credits is not clear.

\section{Conclusion}

The present study showed that there are various approaches to sustainable financing of health promotion services in selected countries and in Iran, including taxes/sin tax on unhealthy foods, sweetened beverages \& services, using the capacities of social insurance funds, and reliance on government public budget. The use of any of these methods or any combination of them depends on the political, social, and cultural structure of each country. Health stewardship in Iran in the policy documents is done by the Ministry of Health. Furthermore, managing the consumption and even interventions that can ultimately lead to the reduction of tobacco addiction should also be defined as health stewardship. In the policymaking system, there is also a need for harmonization of policies for the production, import, and distribution of tobacco and unhealthy foods, sweetened beverages \& services. This monitoring should not be limited to monitoring and controlling the manufacturer and distributor. However, to date, no comprehensive policy has been put in place to address this issue and reduce the consumption of these commodities or their production and distribution process.

\section{Acknowledgement}

The present article was extracted from a Ph.D. thesis in College of Medical Science and Technology, Science and Research Branch, Islamic Azad University.

\section{Conflict of Interests}

The authors declare that they have no competing interests.

\section{References}

1. Lozano R, Naghavi M, Foreman K, Lim S, Shibuya K, Aboyans V, et al. Global and regional mortality from 235 causes of death for 20 age groups in 1990 and 2010: a systematic analysis for the Global Burden of Disease Study 2010. Lancet (London, England). 2012;380(9859):2095-128

2. Alikhani S, Delavari A, Alaedini F, Kelishadi R, Rohbani S, Safaei A. A province-based surveillance system for the risk factors of noncommunicable diseases: A prototype for integration of risk factor surveillance into primary healthcare systems of developing countries. Public Health. 2009;123(5):358-64.

3. Beaglehole R, Bonita R, Horton R, Adams C, Alleyne G, Asaria P, et al. Priority actions for the non-communicable disease crisis. Lancet (London, England). 2011;377(9775):143. ¿ V_ᄉ

4. Tangcharoensathien V, Prakongsai P, Patcharanarumol W, Limwattananon S, Buasai S. Innovative financing of health promotion. 2008

5. Organization WH. Preventing chronic diseases: a vital investment: World Health Organization; 2005.

6. Hsiao WC. Why is a systemic view of health financing necessary? Health Aff. 2007;26(4):950-61.

7. Corbin JH, Mittelmark MB. Partnership lessons from the Global Programme for Health Promotion Effectiveness: a case study. Health Promot Int. 2008;23(4):365-71.

8. Akerman M, Arroyo H, Jones CM, O'Neil M, Roca A, Wallerstein N. Evaluation of health promotion effectiveness: a political debate and/or a technical exercise? Promot Educ. 2007;Suppl 1:13-5.

9. Woolf SH, Dekker MM, Byrne FR, Miller WD. Citizen-centered health promotion: building collaborations to facilitate healthy living. Am J Prev Med. 2011;40(1 Suppl 1):S38-47.

10. McManus A. Health promotion innovation in primary health care. Australas Med J. 2013;6(1):15-8.

11. Schieber G, Maeda A. Health care financing and delivery in developing countries. Health Aff. 1999;18(3):193-205.

12. McQuestion M, Gnawali D, Kamara C, Kizza D, Mambu-Ma-Disu $\mathrm{H}$, Mbwangue J, et al .Creating sustainable financing and support for immunization programs in fifteen developing countries. Health Aff. 2011;30(6): 1134-40.

13. Dain K. Sustainable financing: the Achilles heel of the noncommunicable diseases response. Lancet Diabetes Endocrinol. 2015;3(12):923-5.

14. Kirigia JM, Preker A, Carrin G, Mwikisa C, Diarra-Nama AJ. An overview of health financing patterns and the way forward in the WHO African Region. East Afr Med J. 2006;83(9 Suppl):S1-28.

15. Moszynski P. Cambodia's AIDS strategy could fail without sustainable financing. BMJ. 2010;341:c7301.

16. Andreyeva T, Long MW, Brownell KD. The impact of food prices on consumption: a systematic review of research on the price elasticity of demand for food. Am J Public Health. 2010;100(2):21622.

17. Moodie R, Stuckler D, Monteiro C, Sheron N, Neal B, Thamarangsi $\mathrm{T}$, et al. Profits and pandemics: prevention of harmful effects of tobacco, alcohol, and ultra-processed food and drink industries. Lancet (London, England). 2013;381(9867):670-9.

18. Mytton O, Gray A, Rayner M, Rutter H. Could targeted food taxes improve health? J Epidemiol Community Health. 2007;61(8):689-94.

19. Bayarsaikhan D. Financing health promotion in Japan and Mongolia. Bulletin of the World Health Organization. 2008;86(11):896-7.

20. Bayarsaikhan D, Nakamura K. Health promotion financing with Mongolia's social health insurance. Asia-Pac J Public Health 2015;27(2):887-96.

21. Bayarsaikhan D, Nakamura K. Health promotion financing with Mongolia's social health insurance. Asia-Pac J Public Health. 2009;21(4):399-409.

22. Cashin C, Sparkes S, Bloom D. Earmarking for health: from theory to practice. Geneva :World Health Organization; 2017. Report No.: 9241512202

23. Vathesatogkit P, Lian T, Ritthiphakdee B. Health promotion fund: sustainable financing and governance. Bangkok: Thai Health Promotion Foundation. 2013.

24. Arsenijevic J, Groot W, Tambor M, Golinowska S, Sowada C, Pavlova M. A review of health promotion funding for older adults in Europe: a cross-country comparison. BMC Health Serv Res. 2016;16 Suppl 5:288. 
25. Elovainio R, Evans DB. Raising more domestic money for health: prospects for low- and middle-income countries. Health Econ Policy Law. 2017;12(2):139-57.

26. Slama K. Background information for adopting a policy encouraging earmarked tobacco and alcohol taxes for the creation of health promotion foundations. Promot Educ. 2006;13(1):30-5, 56-62, 74-9.

27. Prakongsai P, Patcharanarumol W, Tangcharoensathien V. Can earmarking mobilize and sustain resources to the health sector? Bulletin of the World Health Organization. 2008;86(11):898-901.

28. Nam EW, De Leeuw E, Moon JY, Ikeda N, Dorjsuren B, Park MB. Sustainable funding of health initiatives in Wonju, Republic of Korea via a tobacco consumption tax. Health Promot Int. 2011;26(4):457-64.

29. Jimenez-Ruiz JA, Saenz de Miera B, Reynales-Shigematsu LM, Waters HR, Hernandez-Avila M. The impact of taxation on tobacco consumption in Mexico. Tob Control. 2008;17(2):105-10.

30. Evans T, Pablos-Mendez A. Shaping of a new era for health financing. Lancet (London, England). 2016;387(10037):2482-4.

31. Goodchild M, Perucic AM, Nargis N. Modelling the impact of raising tobacco taxes on public health and finance. Bulletin of the World Health Organization. 2016;94(4):250-7.

32. Banks C, Rawaf S, Hassounah S. Factors influencing the tobacco control policy process in Egypt and Iran: a scoping review. Glob Health Res Policy. 2017;2:19. 